University for Business and Technology in Kosovo

UBT Knowledge Center

UBT International Conference

2017 UBT International Conference

Oct 29th, 11:00 AM - 1:00 PM

\title{
The influence of the radius of the curve and the lateral slope on the safety of the vehicle
}

\author{
Baxhuku Visar \\ Universtieti i Prishtinës, visar.baxhuku@uni-pr.edu \\ Koca Odisea \\ Polytechnic University of Tirana, okoca@upt.al \\ Çekiçi Visar \\ Polytechnic University of Tirana, vcekici@upt.al
}

Follow this and additional works at: https://knowledgecenter.ubt-uni.net/conference

Part of the Civil Engineering Commons

\section{Recommended Citation}

Visar, Baxhuku; Odisea, Koca; and Visar, Çekiçi, "The influence of the radius of the curve and the lateral slope on the safety of the vehicle" (2017). UBT International Conference. 50.

https://knowledgecenter.ubt-uni.net/conference/2017/all-events/50

This Event is brought to you for free and open access by the Publication and Journals at UBT Knowledge Center. It has been accepted for inclusion in UBT International Conference by an authorized administrator of UBT Knowledge Center. For more information, please contact knowledge.center@ubt-uni.net. 


\title{
The influence of the radius of the curve and the lateral slope on the safety of the vehicle
}

\author{
Baxhuku Visar $^{1}$, Koca Odisea ${ }^{2}$ \\ ${ }^{1}$ Universtieti i Prishtinës, Fakulteti i Inxhinierisë Mekanike \\ 2, Universtieti Politeknik i Tiranës, Fakulteti i Inxhinierisë Mekanike \\ visar.baxhuku@uni-pr.edu, okoca@upt.al,
}

\begin{abstract}
The movement of the vehicle in a curve related to the construction of the road is expressed through the influence of the radius of the curve and the transversal inclination of the road. Two of these quantities are fixed quantities ever since the projection and then construction phase of the road. During the vehicle's movement in the curve, their influence is shown through the critical slide velocity. This critical velocity is defined from the influence of the centrifugal force. For smaller values under critical velocity, this influence is expressed through the safety of the movement or the comfort of the driver and passengers in the vehicle. The gained values of the critical velocity are displayed in the table of values of the influential parameters.
\end{abstract}

Keywords: Radius, slope, velocity, force.

\section{Introduction}

The velocity of the vehicle in the curve is influenced by the forces which move the vehicle, the resistances of the velocity and also the centrifugal force which attempts to displace the vehicle in the outer part of the curve or to displace from the desired trajectory of movement. The displacement from the trajectory is not immediate, but gradual and is realized through the slide into the side direction of the wheel proportionally to the surface of the road. For this reason, the critical slide velocity is accounted as a criteria for the safety of movement of the vehicle. 


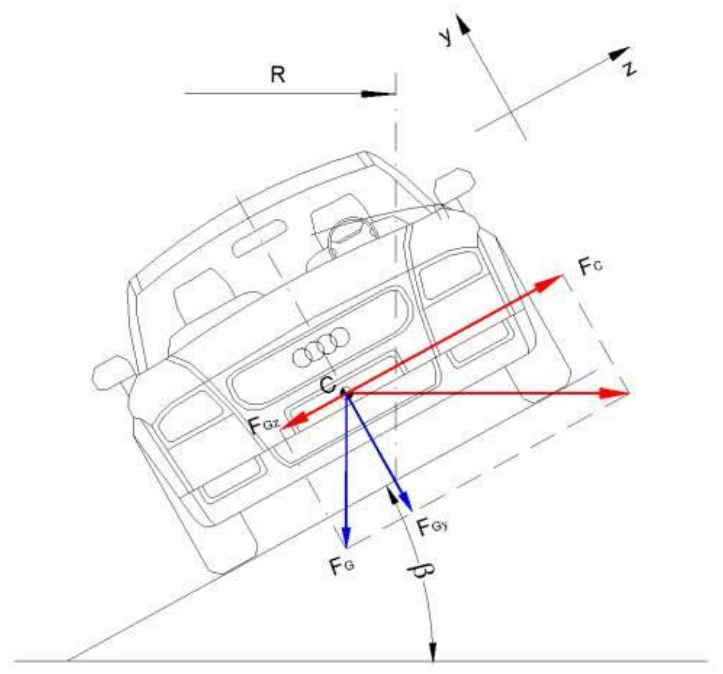

Fig. 10. The forces which influence on the vehicle during movement in curve with lateral slope

\section{The expressions for defining the critical slide velocity of the vehicle during movement in curve}

For the vehicle to be in the borders of stability the force of friction must be equal with the sum of the side forces. Meanwhile, to eliminate sliding towards the side in the direction of the radius of the curve, the sum of the forces on the $\mathrm{Z}$ axis must be lower or equal to the force of friction:

$$
\sum F z=F c_{z}-G z-F_{t}=F c \cdot \cos \beta-G \cdot \sin \beta-F_{t} \leq 0
$$

After the breakdown of the forces in the proper direction according to the axis, the transformations of the equations and the abstraction of smaller values (approximate to zero), the formula for the calculation of the vehicle's critical velocity is presented in this form:

- If the road in the curve with no transversal slope (angle $\beta=0$ and $P=0 \%$ ), then the critical slide velocity is:

$$
v_{\text {rresh }}=\frac{V}{3.6}=\sqrt{g \cdot R \cdot \mu_{t}}[\mathrm{~m} / \mathrm{s}\rfloor
$$

-Critical slide velocity of the vehicle in a horizontal curve with a known radius $\mathrm{R}$ and the lateral slope of the road $\beta$ : 


$$
v_{\text {rresh }}=\sqrt{g \cdot R \frac{\sin \beta+\mu_{t} \cdot \cos \beta}{\cos \beta-\mu_{t} \cdot \sin \beta}} \quad[\mathrm{m} / \mathrm{s}]
$$

For further discussion the formula for the calculation of the critical slide velocity of the vehicles during movement in the curve for the case where we have known the radius of the curve and transversal slope of the road.

From these formulas (2) and (3), the value of the critical velocity is dependent on the radius of the curve $\mathrm{R}$, the transversal slope $\beta$ and the transversal coefficient of friction.

The values of the radius of the curve are dependent on the character of the road (the projected speed). According to the character of the road, the values of the radius of the curve are presented in table form.

Table 1

\begin{tabular}{|l|c|c|c|}
\hline Category of the road & $\begin{array}{c}\text { Projected Speed } \\
\mathrm{V}_{\mathrm{p}}[\mathrm{km} / \mathrm{h}]\end{array}$ & $\begin{array}{c}\text { Radius of the curve } \\
\mathrm{R}_{\min }[\mathrm{m}]\end{array}$ & $\begin{array}{c}\text { Longitudinal slope } \\
{[\%]}\end{array}$ \\
\hline Autoroad & $80-120$ & $250-750$ & $4-6(7)$ \\
\hline Class I & $70-100$ & $180-450$ & $5.5-7$ \\
\hline Class II & $60-100$ & $120-450$ & $5.5-8$ \\
\hline Class III & $50-90$ & $80-350$ & $6-9$ \\
\hline Class IV & $40-80$ & $50-250$ & $7-11$ \\
\hline Class V & $40-70$ & $50-180$ & $8-12$ \\
\hline
\end{tabular}

The values of the transversal coefficient of friction are dependent on the surface of the road, the type of building material and it's condition. In table form, the values of the transversal coefficient of friction are displayed in the following pages.

The transversal slope of the road can achieve the value that may lead to the endangerment of the stability of the vehicle- the slide on the inside part of the curve. The condition that must fulfilled so the vehicle may not slide into the inside part of the curve is:

$$
\operatorname{tg} \beta=\mu_{t}
$$

So, for values equal to and smaller than $\operatorname{tg} \beta<\mu_{t}$, the vehicle will not slide into the inner part of the curve. The maximal value of $\mu_{t}$ is $\mu_{t}=0.6$. The values of the transversal slope of the road in the curve comes to the borders of $2.5 \%-6 \%$. In special cases, it can be taken up to the value of $7 \%$. 
Table 2. The histogram of the defining of the transversal coefficient of friction.

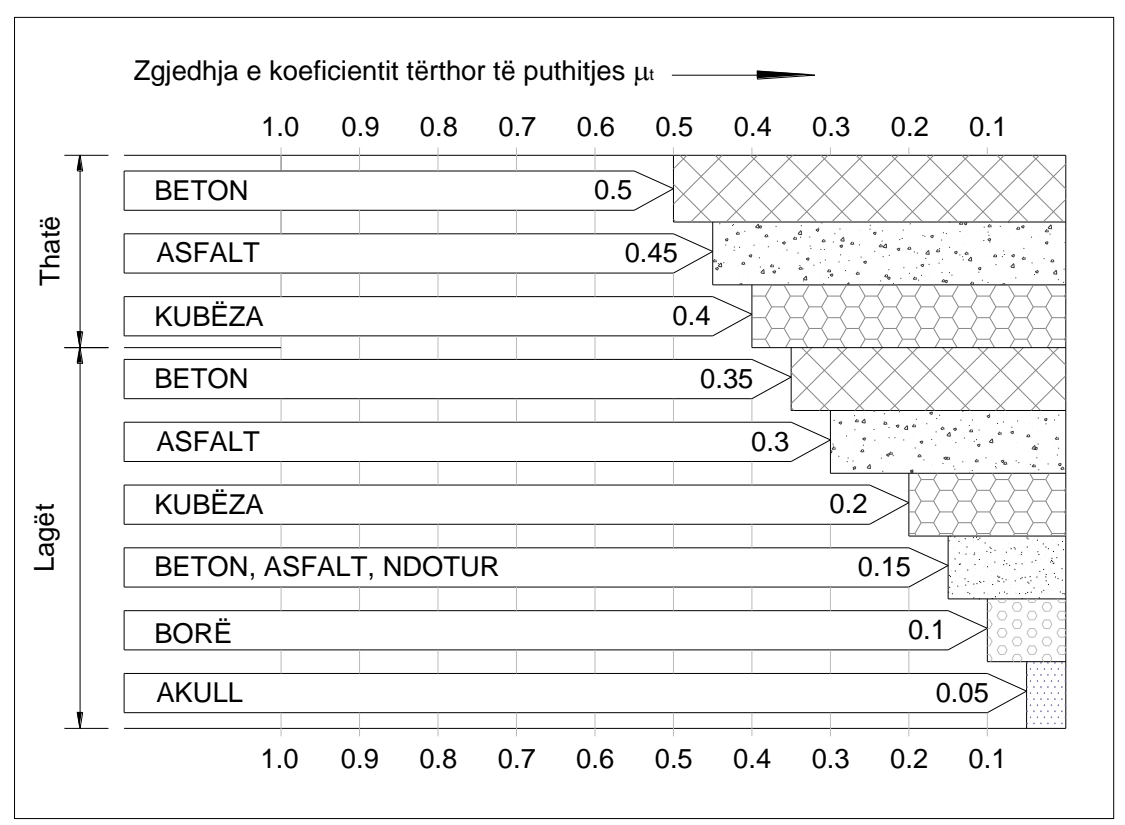

The graphical display of the influence of the radius of the curve and the transversal slope

The graphical display of the slope of the influence of the radius of the curve and the transversal slope on the stability of the vehicle during the movement in the curve can be separated on the dependence of one parameter and two parameters at the same time. 


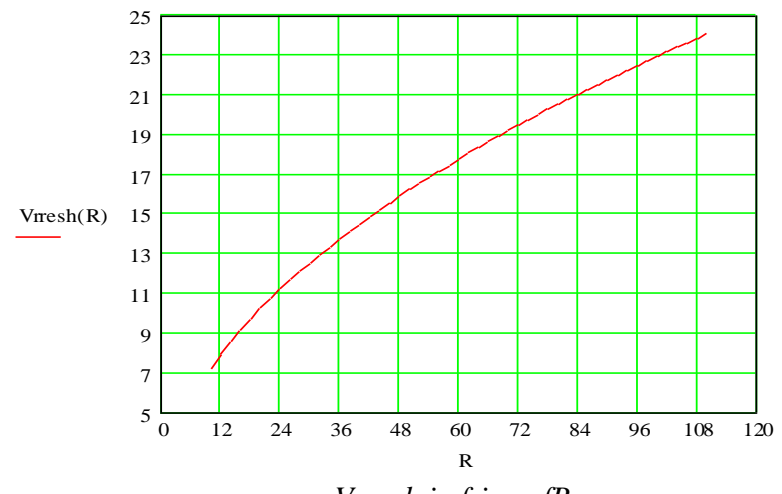

Vrresh in f-ion ofR

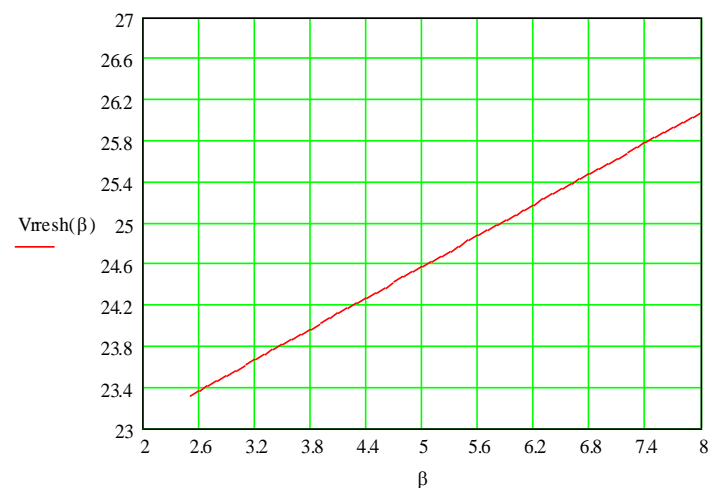

Vrresh in f-ion of $\beta$

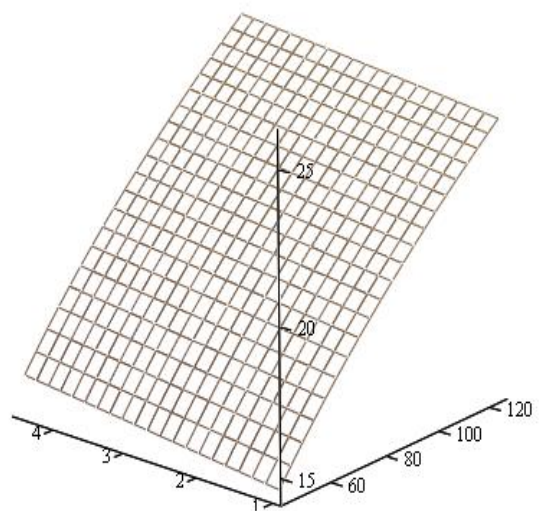

Vrresh in f-ion of $R$ and $\beta$ 


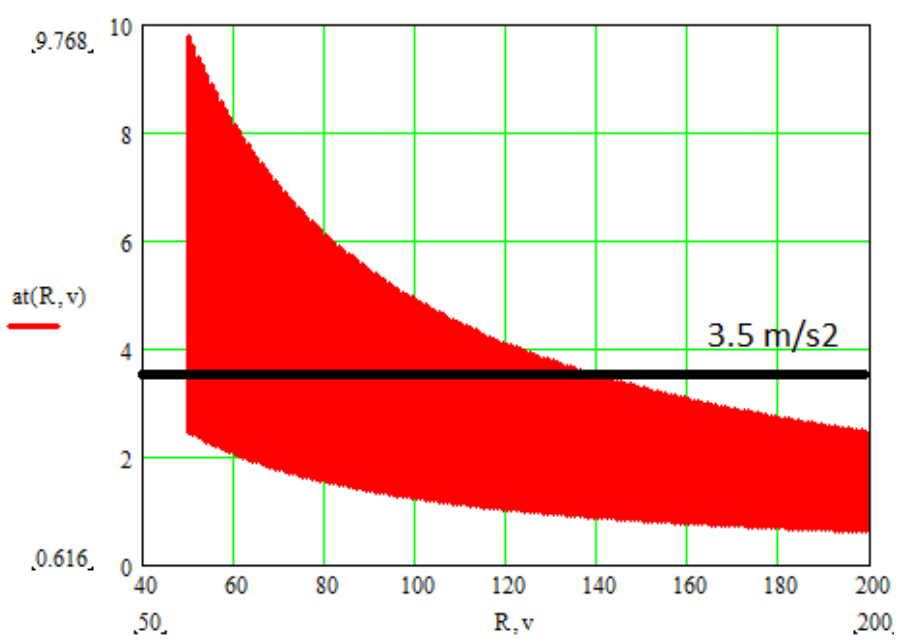

Fig.2 Margins of values for lateral acceleration in $\mathrm{f}$-ion of $\mathrm{v}$ and $\mathrm{R}$

\section{Conclusion}

While analyzing the numerical values of the critical slide velocity, in dependence with the change in the values of the radius of the curve and the lateral slope of the road, we can conclude:

-the minimal values of the radius of the curve and the lateral slope of the road generate higher values of the lateral acceleration of the vehicle, with which we have lower comfort of the driver and passengers,

- in the critical minimal values of the radius of the curve and the lateral slopes we have the danger of the slide of the vehicle, and at the same time lowers safety of the driver and passengers,

-the optimal values of the critical slide velocity are achieved for the optimal values of the radius of the curve and the transversal slope of the road.

\section{References}

1. Doceva, Radojka: Universitet “Cv Kiril I Metodi”. Proektiranje Patista (2004) $139,264,266$

2. .Henning Wallentonwitz, "Automotive Engineering II, Lateral Vehicle Dynamics" Aachen, 2004,

3. . Georg Rill, "Vehicle Dynamics" Regensburg 2009,

4. . Franko Rotim,"Elementi Sigurinsoti cestovnog prometa I" Zagreb,1998

5. . Visar Baxhuku, "Shpejtësia kufitare e lëvizjes së automjetit në kthesë” Prishtinë 2007 (MA Thesis)

6. . Inventure FMS Gateway, Hungary, http://fms-gateway.com/xl_meter_en.. 